\title{
Proceedings
}

\section{Savannas are More Responsive to Rainfall Variability than Riparian Forests ${ }^{\dagger}$}

\author{
Marcio Baldissera Cure ${ }^{1 *}$, Bernardo Monteiro Flores ${ }^{1,2}$, Matheus Bonifácio Pamplona ${ }^{3}$, \\ Rafael Silva Oliveira ${ }^{4}$ and Marina Hirota ${ }^{1,5}$ \\ 1 Universidade Federal de Santa Catarina (UFSC) (Brazil); \\ 2 bmflores@gmail.com \\ ${ }^{3}$ Exeter University (UK); matheusbpamplona@outlook.com \\ ${ }^{4}$ Universidade Estadual de Campinas (UNICAMP) (Brazil);rafaelsoliv@gmail.com \\ 5 marinahirota@gmail.com \\ * Correspondence: marciobcure@gmail.com \\ + Presented at the 1st International Electronic Conference on Forests, 15-30 November \\ 2020;
}

Available online: https://sciforum.net/conference/IECF2020

Published: 25 October 2020

\begin{abstract}
Under the current change in precipitation regime, carbon balance in the tropics may be impacted through responses of drought-threatened vegetation. We aim to understand how forests and savannas under the same precipitation regime respond in terms of GPP to rainfall seasonality. We hypothesize that savannas respond faster to precipitation by changing their GPP inferred through the EVI2, particularly when the woody and herbaceous layer are included. We sampled tree cover in savannas and in riparian evergreen forests, at the Chapada dos Veadeiros National Park (PNCV), located within the Cerrado biome, in Brazil. We calculated the coupling between time series of both EVI2 from Landsat8 and the monthly precipitation calculated from CHIRPS dataset. Forests and savannas respond differently to rainfall seasonality. We found that maximum coupling in savannas is greater than in forests. However, when only trees are considered, savannas and forests have similar responses. Nonetheless, savannas respond faster than forests to rainfall. Furthermore, riparian forests present an increasing greening during the dry season. Our results indicate that GPP of forests and savannas at the PNCV are controlled by different factors because of the differences in the response time of forest and savanna to rainfall seasonality.
\end{abstract}

Keywords: GPP; remote sensing; resilience; Cerrado; drought; savanna; forest

\section{Introduction}

Ecosystem functions such as the gross primary productivity (GPP) depend on the interactions that emerge from biodiversity and its environment [1]. For example, drought extremes may negatively affect GPP in the tropics [2]. In the tropics, where precipitation and fire regimes allow the existence of forests and savannas [3-5], there are heterogeneous distribution of water availability related to plant distribution 
patterns [6], such as those found in the Brazilian Cerrado. Vegetation is extremely dynamic and may change to an alternative state if submitted to a gradual change (or an anomalous pulse event) that may exceed its self organizing capacity [7]. Forests and open environments may also represent alternative functional states, regarding, for example, tree height [8]. In this way, these alternative structural states may be also functionally distinct [9-11] and consequently present distinct responses to changes in environmental drivers, such as those related to precipitation variability [12].

Systems exposed to a more variable environment may have a higher selforganization capacity [13]. For example, studies have shown that forests submitted to a higher rainfall variability are more resistant to drought events $[14,15]$. Current studies on the coupling between drought (e.g. SPI) and vegetation indices (e.g. NDVI, EVI as photosynthetic efficiency) generally focus on large scale patterns, and only in forest and not in savanna ecosystems (e.g. [16]). It is also known that the coupling may be more pronounced for arid or semi-arid regions [17-19], and that water use efficiency and hydrological resilience is greater for drier areas [20]. Locally, responses to precipitation variability in terms of greenness may depend on the vegetation type [19]. Therefore, understanding how distinct vegetation types respond in terms of GPP to rainfall variability is fundamental to capture how savannas and forest dynamics may be affected by extreme precipitation events. However, this discussion still lacks information on how forests and savannas under the same precipitation regime respond to rainfall seasonality in terms of GPP.

Based on the combination of satellite data and field sampling, this study aims at investigating such responses. We hypothesize that the distinct ways savannas and forests respond to rainfall seasonality affect the overall ecosystem functioning in terms of productivity.

\section{Methods}

We performed our study at the Chapada dos Veadeiros National Park (PNCV) (Figure 1), located within the Cerrado biome, in Brazil. We choose the PNCV because its landscapes are heterogeneous, and thus present various phytophysiognomies (e.g. cerrado stricto sensu, riparian evergreen forests, dry forests, palm swamps, grasslands) characterized by a wide range of tree coverages, all within the same large-scale precipitation regime.

The large-scale rainfall regime at PNCV features mean annual precipitation of around $1400 \mathrm{~mm} /$ year and a marked dry season of around 5 to 6 months. 


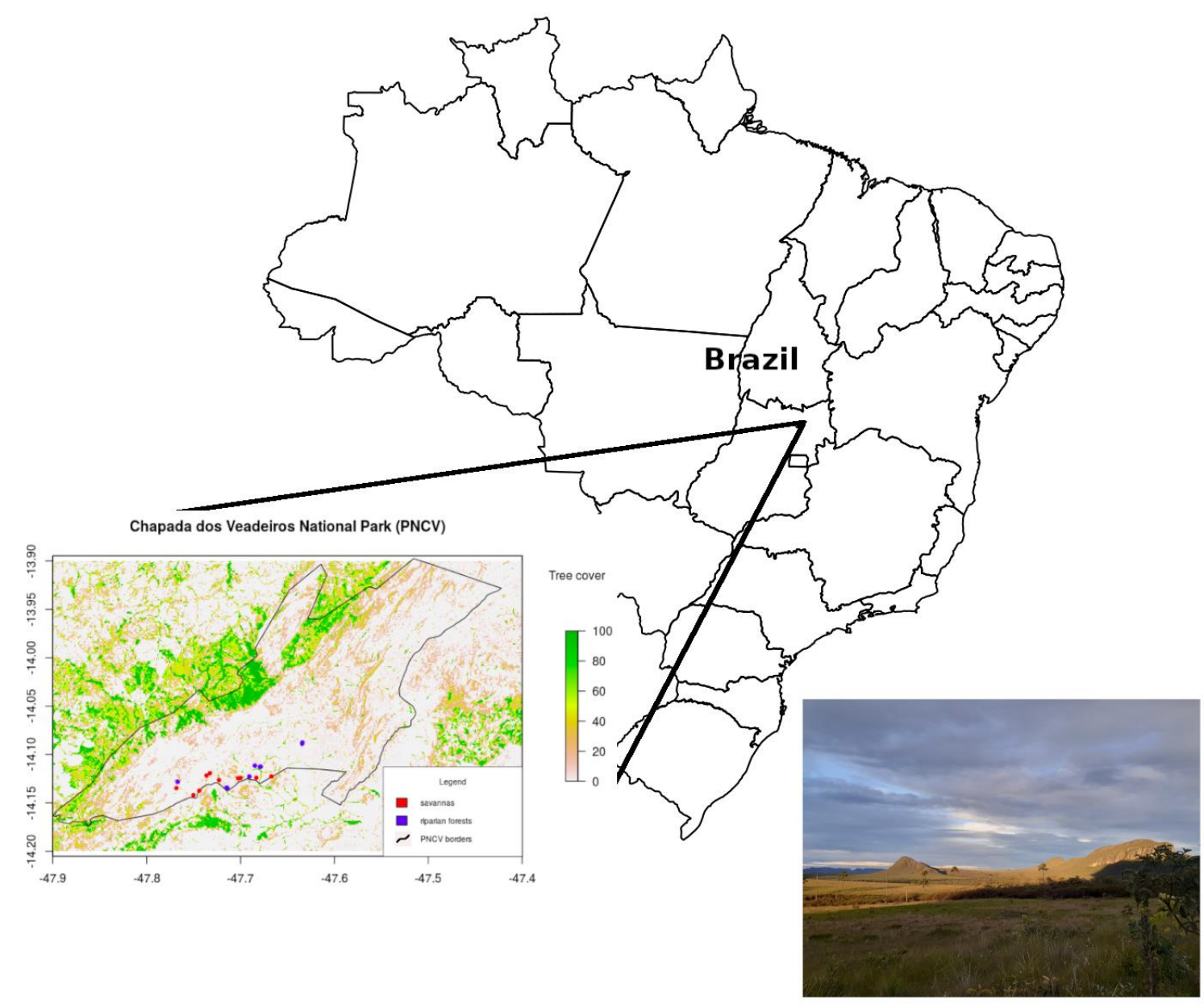

Figure 1. Sample plots (blue - riparian forests, red - savannas) at Chapada dos Veadeiros National Park (black line). The photo illustrates the park area. Photo by Marcio Cure.

\subsection{Sample plots}

We sampled a total of $20\left(200 \mathrm{~m}^{2}\right)$ field plots, from which 10 were located in cerrado stricto sensu physiognomy (savanna) and 10 in riparian forests (Figure 1). The sample efforts were performed in the end of the rainy season, in April, 2019. Plots were randomly selected according to classes of tree cover percentages from Hansen et al [21]. Savannas are characterized by tree cover between 5 and $70 \%$, whereas forests by tree cover higher than $70 \%$ [22]. For each plot, we measured tree cover using a concave densiometer in all four plot corners, and for each corner the measurements were made in four directions (i.e. N, S, E, W). The resulted tree cover is the mean of all measured values (16 values) for each sample plot.

\subsection{Satellite data}

\subsubsection{EVI2}

We extracted the 2-band Enhanced Vegetation Index (EVI2, https://www.indexdatabase.de/db/si-single.php?sensor id=168\&rsindex id=237):

$E V I 2=2.4($ band $5-$ band 4$) /($ band $5+$ band $4+1)$ 
from Landsat8 using the Tucumã tool [23]. The EVI2 was developed to have the efficiency of EVI and avoid saturation at high biomass while minimizing atmosphere and soil influences without the blue band [24].

The resolution of the data from Landsat8 is $30 \times 30 \mathrm{~m}$, and is available for every 16 days. After filtering the EVI2 data using the quality flag file that contain information about the cloud mask for the scene (http://www.landsat.usgs.gov), we extracted the values for each sample plot and calculated the mean for each month from April, 2013 to June, 2018.

Overall riparian evergreen forests sampled at the PNCV have a narrow width and long extensions as they occur along streams. Consequently, some bias may impact the EVI2 results once the Landasat8 image pixel size is more than 3-times our sample plots size.

\subsubsection{Precipitation}

We also downloaded a daily time series of precipitation with approximated $5 \mathrm{x}$ $5 \mathrm{~km}$ resolution from the CHIRPS dataset (https://data.chc.ucsb.edu/products/CHIRPS-2.0/), extracted the time series for each sample plot and calculated the mean for each month.

\subsection{Coupling between EVI2 and precipitation}

We defined the coupling using the Kendall tau, calculated as the correlation between the EVI2 and precipitation time series for each sample plot. In savannas where trees and grasses co-exist [25], we calculated two coupling values: 1) ecosystem value, accounting for both tree and grass coverage; and 2) tree cover value, performing an standardization according to the measured tree cover to account only for the effect savanna trees have on the EVI2.

We also investigated the lag that the maximum correlation between EVI2 and precipitation occurs for each sample plot, using a cross-correlation function analysis.

We performed a Student's t-test to compare the coupling of forests and savannas and to compare the coupling of trees from both ecosystems. All analyses were performed with R 3.6 [26].

The manuscript data are available online at https://github.com/marciocure/cure_et_al_iecf_2020.

\section{Results}

We found distinct responses to precipitation for forests and savannas at the PNCV (Figure 2; Table 1). Maximum coupling between productivity and precipitation for savannas is greater than for forests $(t=5.365, p=0.00038)$ (Figure $2 b$ ). When considering only trees in both ecosystems, we also found distinct responses $(t=2.012, p=0.07)$ (Figure $2 c)$ regarding 1$)$ the greater variation and 2$)$ the negative coupling values in forest responses. Furthermore, savannas respond faster than forests $(t=-4.1912, p=0.001357)$ with the time lag spanning from 0 to 1 month (Figure 
2a; Figure 3). The maximum coupling for forests lags 2.5 months on average, with a minimum of 1 and a maximum of 5 months. Although tree-max-coupling is in general similar ( $t=2.012, p=0.07$; Figure $2 c)$, negative maximum coupling values for forests indicate that decreases in precipitation occur with increases in productivity (Figure 3b; Figure 4). On the other hand, in savannas, maximum coupling is overall positive (Figure 3a; Figure 4). Furthermore, the coupling magnitude (i.e. absolute values) is also greater for savannas (ecosystem level) (Table 1), but when considering only trees, forest trees present a higher absolute coupling value than savannas (Table $1)$.
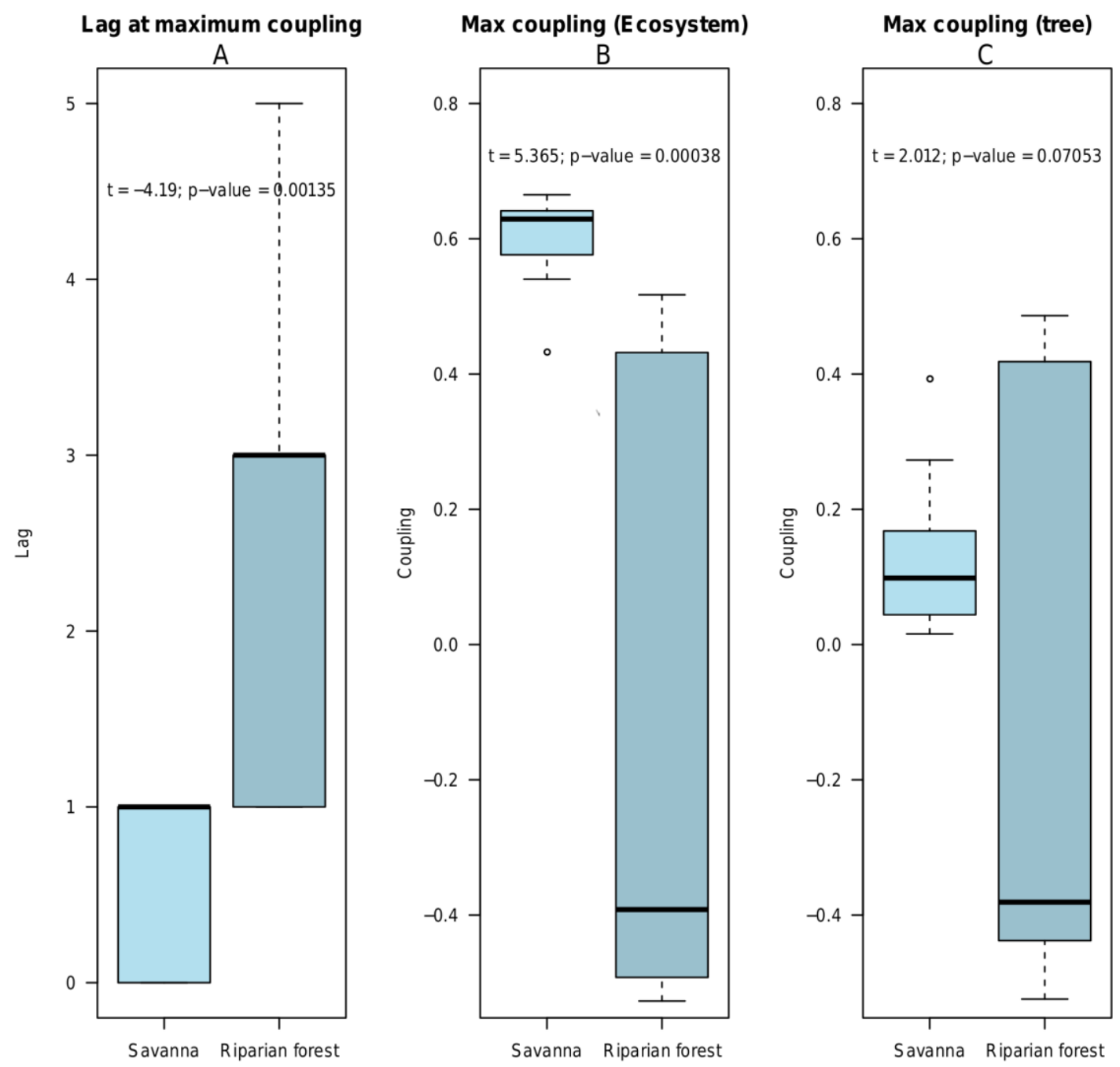

Figure 2. Distribution of responses regarding the (A) lag in response to precipitation, (B) maximum coupling for ecosystems, and (C) maximum coupling considering only trees.

Table 1. Student's t test comparing coupling between greeness and precipitation for forests and for savannas at the PNCV. .
$\mathrm{t}$
df
p-value ${ }^{1}$
Ecosystem 


$\begin{array}{llll}\text { Ecosystem }\left(\mathrm{abs}^{2}\right) & -4.692693 & 17.64299 & 0.0001906804 \text { * } \\ \text { Trees } & -2.01268 & 10.48863 & 0.07053421 \\ \text { Trees }\left(\mathrm{abs}^{2}\right) & 6.212402 & 15.84881 & 1.297914 \mathrm{e}-05 \text { * } \\ \text { Lag at max coupling } & 4.191213 & 11.55334 & 0.00135681 \text { * }\end{array}$

$\left[{ }^{1}\right]$ * Significant values; $\left[{ }^{2}\right]$ absolute values meaning the strongest of the coupling.

A IS1

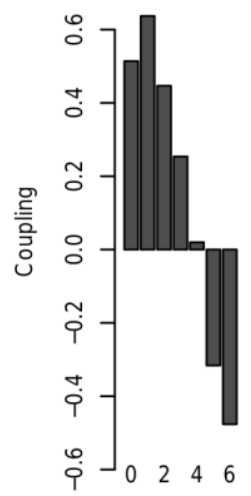

Lag

ES4

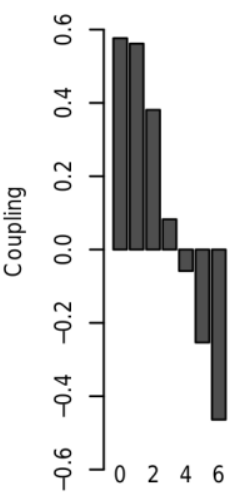

Lag
IS2

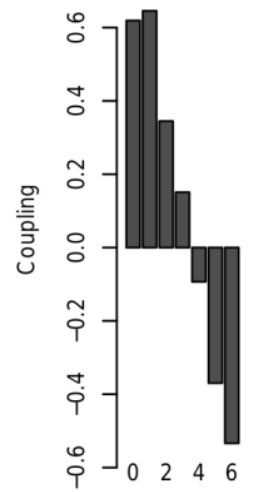

Lag

BS1

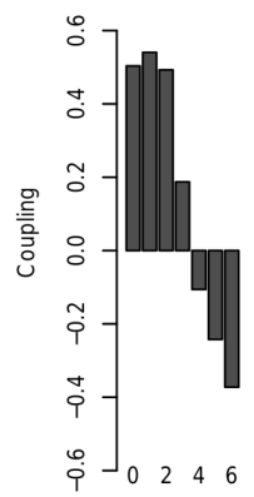

Lag
IS5

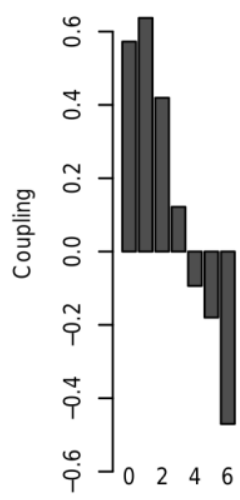

Lag

BS2

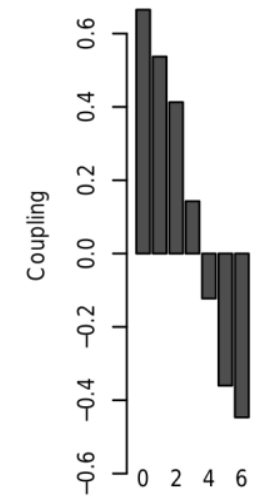

Lag
ES1

ES3
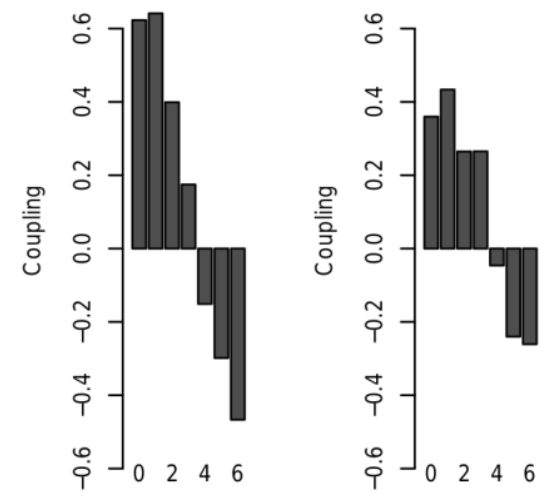

Lag

Lag

MS1

MS2
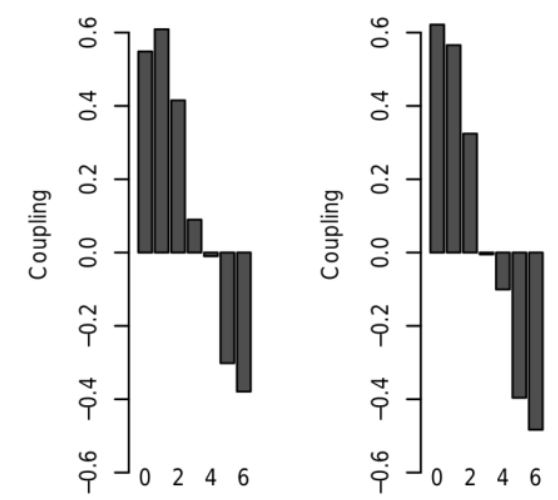

Lag

Lag 
B IC3

EC2

EC3

BC1

BC2

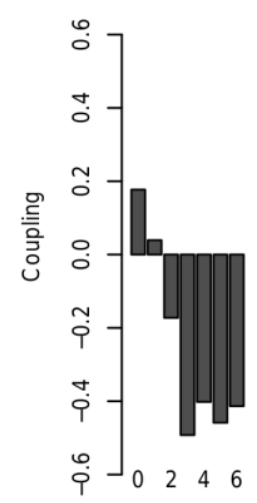

Lag

BQ8

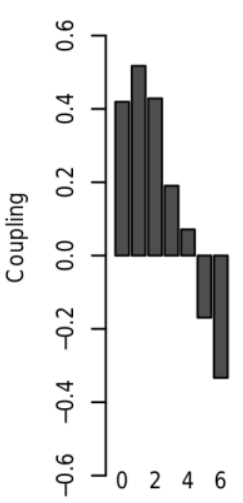

Lag

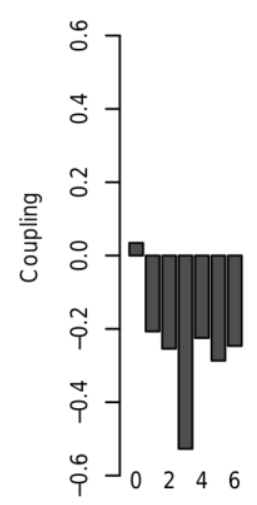

Lag

RC1

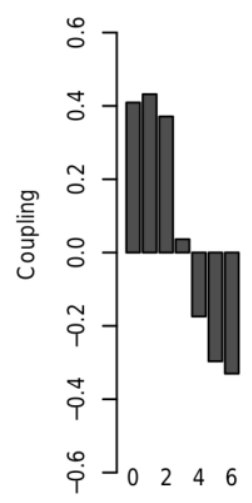

Lag

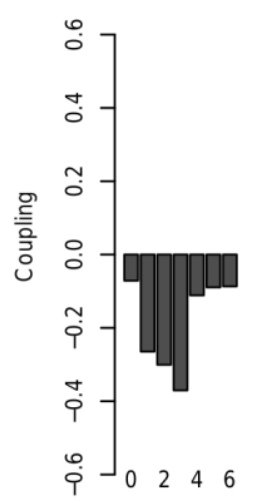

Lag

RC2

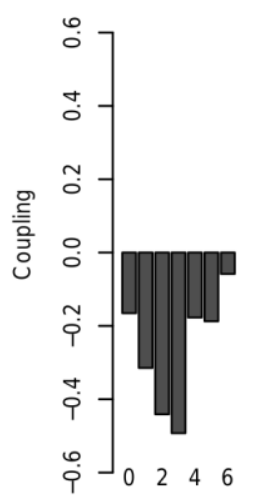

Lag

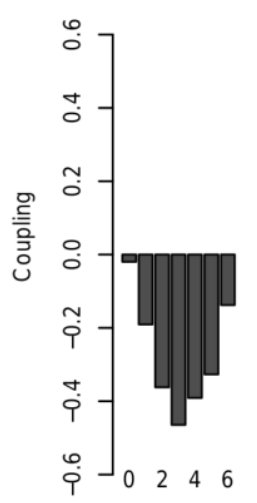

Lag

RC3
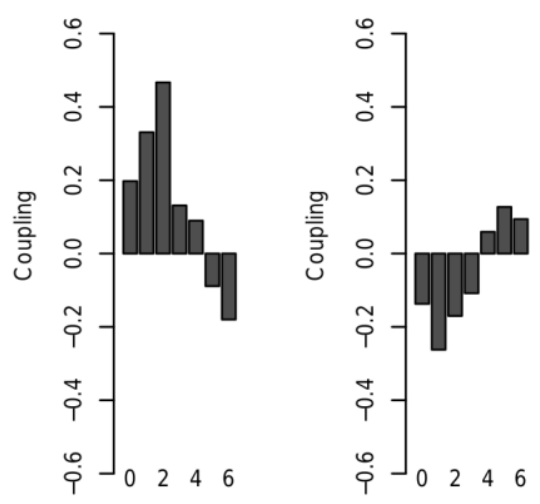

Lag

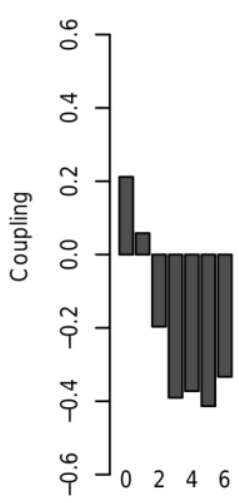

Lag

MC 1

Figure 3. Coupling between EVI2 and precipitation with different lags for (A) savannas, and for (B) forests. IS1, IS2, IS5, ES1, ES3, ES4, BS1, BS2, MS1, MS2 are the savanna plots. IC3, EC2, EC3, BC1, $\mathrm{BC} 2, \mathrm{BQ} 8, \mathrm{RC1}, \mathrm{RC} 2, \mathrm{RC} 3, \mathrm{MC} 1$ are the forest plots. 


\section{Mean EVI2 and precipitation at the PNCV}

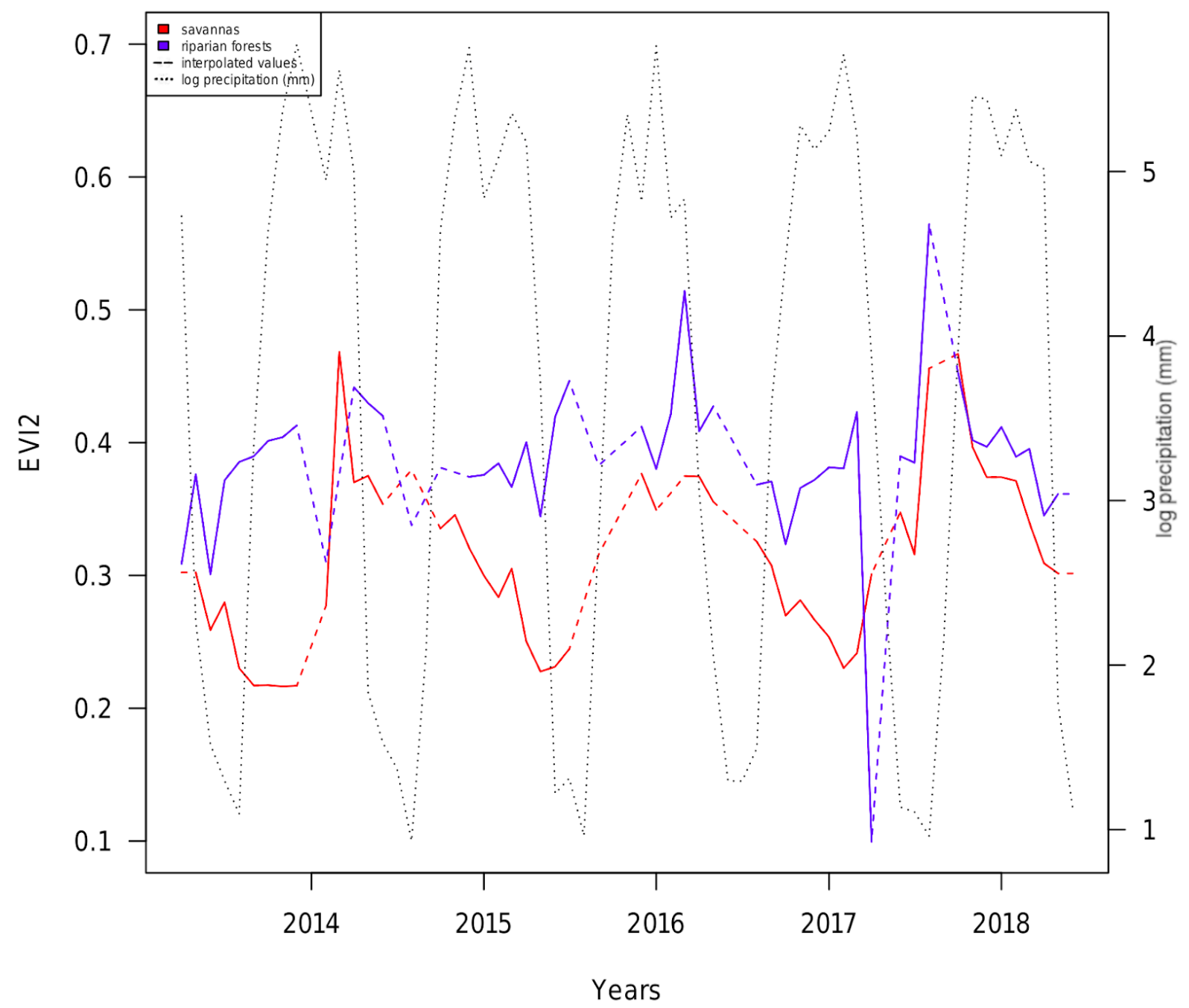

Figure 4. Mean EVI2 for riparian evergreen forests (blue) and savanna (red) at PNCV. Forests seem to increase productivity during dry season

\section{Discussion}

Our results show that the relationship between precipitation and productivity for savannas and riparian forests at the PNCV differs substantially.

As a general ecosystem function, GPP, is likely to be an emergent property resulting from the interactions of several elements. GPP depends on the water and light availability [27], further on other resources and environmental conditions, such as solar radiation [28], nutrient availability [29], soil toxicity [30], temperature [31], and topography [19].

Riparian forests at the PNCV present an increasing greening during the dry season (Figure 4). The negative maximum coupling for most forest plots and the largest mean lag suggest that forests increase their productivity during and after the dry season and potentially after anomalous droughts. It may be explained by the 
higher evaporative demand from the atmosphere when the temperatures are higher because of the large-scale air subsidence (leading to lower relative humidity) combined with the proximity of the water table in riparian evergreen forests. These kind of response were reported before for tropical forests [32-34], with a potential explanation linked to the trade-off between drought-avoidance and droughttolerance in which larger trees would have more access to deep waters than smaller ones, but they would also be more vulnerable to embolism than smaller trees [35]. It is not the case here, because riparian evergreen forests and savannas are subjected to different conditions (e.g. soil characteristics, water availability) in different environments due to the heterogeneity of the landscape. Water is not a limiting resource for the riparian forests at the PNCV because they are close to the water table and thus have water access throughout the year. The reasoning to explain the positive responses to decreased precipitation may be related to deciduousness [36].

For Amazonian trees, the ontogeny of leaves are linked to photosynthetic efficiency where leaf turnover patterns may be crucial in explaining similar evergreen forest productivity during dry seasons [37]. Furthermore, sunlight may be more available during the dry season (given the air subsidence), and clouds may act as a negative factor to control GPP in the wet season. Another plausible explanation, still to be tested, is that the productivity of the riparian forests may be affected by the groundwater regime which might be decoupled from precipitation. Therefore, our results may indicate a possible causal relation between the time of response and the connectivity with environments submitted to distinct precipitation regimes.

We presume that the competition for light is as important for forest trees as is water for savanna trees based on the forest greening during the dry season. Our results point to the existence of a trade-off between distinct strategies [35]. For instance, severe droughts may imply more vulnerability for higher trees due to the increasing tension in the water column with increasing tree height [38,39]. Furthermore, the higher the trees the higher the energy costs to rebuild xylem after the occurrence of embolisms [40]. On the other hand, tree size (i.e. diameter at breast height) is an indicator of root depth, which would allow for the use of deep water and its redistribution when the surface is dry. Moreover, traits related to root depth are good predictors of vegetation responses to precipitation changes [41].

According to our hypothesis, savannas are more responsive to precipitation seasonality than forests. In savannas the critical resource is water, so trees have mechanisms to avoid loss of water and hydraulic failure, such as stomatal control and adjustments in leaf area [42]. Furthermore, there are other environmental filters acting on the systems. For example, soil organic carbon content combined with granulometry may influence water retention [43]. Variation in water and air permeability is also influenced by soil structure with lower variation occurring in sandy soils [44]. Fine soil granulometry is an indicator of high adsorption of water and nutrients because the smaller the particle size, the more the contact surface and the higher the cation exchange capacity [27]. As the proportion of evergreen trees 
seems to be lower for savannas, deciduousness may also control water loss, and trees may contribute to a lower variability in the ecosystem greenness through redistribution mechanisms [45].

Further studies should be performed to reproduce our methods and to test hydraulic and fire traits as explanatory variables to the coupling.

\section{Conclusions}

Quantitative and mechanistic understanding of plant-communities' responses to precipitation is of major importance to better predict vegetation losses. Our results indicate that the GPP may depend on the proximity of the water table at the PNCV. Furthermore, forests at the PNCV present increasing growth during the dry season such as reported for some Amazonian forests. However, further studies are necessary to understand which mechanisms are driving the patterns found here. Therefore, forests and savannas at the PNCV are functionally distinct, in agreement with structural differences they present, particularly taking into account the differences in the response time and coupling variation between forest and savanna communities.

Supplementary Materials: The following are available online at http://www.xxxxx, Figure S1: title, Table S1: title, Video S1: title.

Author Contributions: M.B.C, B.M.F., R.S.O. and M.H. conceived the study; M.B.C., B.M.F., M.B.P collected data; M.B.C. analyzed data; M.B.C. wrote the first draft. R.S.O., B.M.F., M.B.P., and M.H. reviewed and contributed to the final version.

Acknowledgments: $\mathrm{MBC}$ thanks to Fundação de Amparo à Pesquisa e Inovação do Estado de Santa Catarina (FAPESC) for scholarship, to the Fundo Brasileiro para a Biodiversidade (FUNBIO) and to the Instituto da Humanidade (Humanize) for financing field trips. We also thanks to Isabel Schmidt, Alexandre Sampaio, and to Instituto Chico Mendes de Conservação da Biodiversidade (ICMBio) for facilitate our work in some way.

Conflicts of Interest: The authors declare no conflict of interest. The funders had no role in the design of the study; in the collection, analyses, or interpretation of data; in the writing of the manuscript, or in the decision to publish the results.

\section{References}

1. Costanza, R.; Fisher, B.; Mulder, K.; Liu, S.; Christopher, T. Biodiversity and ecosystem services: A multi-scale empirical study of the relationship between species richness and net primary production. Ecological Economics 2007, 61, 478-491, doi:10.1016/j.ecolecon.2006.03.021.

2. Yuan, M.; Zhu, Q.; Zhang, J.; Liu, J.; Chen, H.; Peng, C.; Li, P.; Li, M.; Wang, M.; Zhao, P. Global response of terrestrial gross primary productivity to climate extremes. Science of The Total Environment 2021, 750, 142337, doi:https://doi.org/10.1016/j.scitotenv.2020.142337.

3. Hirota, M.; Holmgren, M.; Van Nes, E.H.; Scheffer, M. Global resilience of tropical forest and savanna to critical transitions. Science 2011, 334, 232-235, doi:10.1126/science.1210657.

4. Staver, A.C.; Archibald, S.; Levin, S.A. The Global Extent and Determinants of. Science 2011, 334, 230-232, doi:10.1126/science.1210465.

5. Accatino, F.; Michele, C. de Humid savanna-forest dynamics: A matrix model with vegetation-fire interactions and seasonality. Ecological Modelling 2013, 265, 170-179, doi:10.1016/j.ecolmodel.2013.05.022. 
6. Ferreira, J.N.; Bustamante, M.; Garcia-Montiel, D.C.; Caylor, K.K.; Davidson, E.A. Spatial variation in vegetation structure coupled to plant available water determined by two-dimensional soil resistivity profiling in a Brazilian savanna. Oecologia 2007, 153, 417-430, doi:10.1007/s00442-007-0747-6.

7. Van Nes, E.H.; Hirota, M.; Holmgren, M.; Scheffer, M. Tipping points in tropical tree cover: Linking theory to data. Global Change Biology 2014, 20, 1016-1021, doi:10.1111/gcb.12398.

8. Xu, C.; Vergnon, R.; Cornelissen, J.H.C.; Hantson, S.; Holmgren, M.; Nes, E.H. van; Scheffer, M. Temperate forest and open landscapes are distinct alternative states as reflected in canopy height and tree cover. Trends in Ecology and Evolution 2015, 30, 501-502, doi:10.1016/j.tree.2015.07.002.

9. Charles-Dominique, T.; Staver, A.C.; Midgley, G.F.; Bond, W.J. Functional differentiation of biomes in an African savanna/forest mosaic. South African Journal of Botany 2015, 101, 82-90, doi:10.1016/j.sajb.2015.05.005.

10. Yin, Z.; Dekker, S.C.; Hurk, B.J.J.M.V.D.; Dijkstra, H.A. Bimodality of woody cover and biomass across the precipitation gradient in West Africa. Earth System Dynamics 2014, 5, 257-270, doi:10.5194/esd-5-257-2014.

11. Berdugo, M.; Kéfi, S.; Soliveres, S.; Maestre, F.T. Plant spatial patterns identify alternative ecosystem multifunctionality states in global drylands. Nature Ecology and Evolution 2017, 1, 1-7, doi:10.1038/s41559016-0003.

12. Schwartz, N.B.; Lintner, B.R.; Feng, X.; Powers, J.S. Beyond MAP : A guide to dimensions of rainfall variability for tropical ecology. Biotropica 2020, 1-14, doi:10.1111/btp.12830.

13. Holling, C.S. Resilience and stability of ecological systems. Annual Review of Ecology and Systematics 1973, 4, $1-23$.

14. Barros, F. de V.; Bittencourt, P.R.; Brum, M.; Restrepo-Coupe, N.; Pereira, L.; Teodoro, G.S.; Saleska, S.R.; Borma, L.S.; Christoffersen, B.O.; Penha, D. et al. Hydraulic traits explain differential responses of Amazonian forests to the 2015 El Niño-induced drought. New Phytologist 2019, 223, 1253-1266, doi:10.1111/nph.15909.

15. Ciemer, C.; Boers, N.; Hirota, M.; Kurths, J.; Müller-Hansen, F.; Oliveira, R.S.; Winkelmann, R. Higher resilience to climatic disturbances in tropical vegetation exposed to more variable rainfall. Nature Geoscience 2019, 12, 174-179, doi:10.1038/s41561-019-0312-Z.

16. Lotsch, A.; Friedl, M.A.; Anderson, B.T.; Tucker, C.J. Coupled vegetation-precipitation variability observed from satellite and climate records. Geophysical Research Letters 2003, 30, 8-11, doi:10.1029/2003GL017506.

17. Ding, M.; Zhang, Y.; Liu, L.; Zhang, W.; Wang, Z.; Bai, W. The relationship between NDVI and precipitation on the Tibetan Plateau. Journal of Geographical Sciences 2007, 17, 259-268, doi:10.1007/s11442-007-0259-7.

18. Chen, Y.; Uriarte, M.; Wright, S.J.; Yu, S. Effects of neighborhood trait composition on tree survival differ between drought and postdrought periods. Ecology 2019, 100, 1-10, doi:10.1002/ecy.2766.

19. Chen, Z.; Wang, W.; Fu, J. Vegetation response to precipitation anomalies under different climatic and biogeographical conditions in China. Scientific Reports 2020, 10, 1-16, doi:10.1038/s41598-020-57910-1.

20. Xue, B.; Wang, G.; Xiao, J.; Helman, D.; Sun, W.; Wang, J.; Liu, T. Global convergence but regional disparity in the hydrological resilience of ecosystems and watersheds to drought. Journal of Hydrology 2020, 591, 111, doi:10.1016/j.jhydrol.2020.125589.

21. Hansen, M.C.; Potapov, P.V.; Moore, R.; Hancher, M.; Turubanova, S.A.; Tyukavina, A.; Thau, D.; Stehman, S.V.; Goetz, S.J.; Loveland, T.R. et al. High-resolution global maps of 21st-century forest cover change. Science 2013, 342, 850-853, doi:10.1126/science.1244693.

22. Junior, M.C. da S.; Soares-Silva, L.H.; Cordeiro, A.O. de O.; Munhoz, C.B.R. Guia do observador de árvores: tronco, copa e folha; Rede de Sementes do Cerrado: Brasília, 2014; p. 252; ISBN 978-85-99887-10-3.

23. Menini, N.; Almeida, A.E.; Lamparelli, R.; Maire, G.L.E.; Oliveira, R.S.; Verbesselt, J.A.N.; Hirota, M.; Torres, R.D.A.S. Tucumã: A toolbox for spatiotemporal remote sensing image analysis. IEEE Geoscience and Remote Sensing Magazine 2019, 7, 110-122, doi:10.1109/MGRS.2019.2928260.

24. Jiang, Z.; Huete, A.R.; Didan, K.; Miura, T. Development of a two-band enhanced vegetation index without a blue band. Remote Sensing of Environment 2008, 112, 3833-3845, doi:10.1016/j.rse.2008.06.006.

25. Scholes, R.J.; Archer, S.R. Tree-grass interactions in savannas. Annual Review of Ecology and Systematics 1997, 28, 517-554, doi:0066-4162/97/1120-0517.

26. R Core Team R: A language and environment for statistical computing; R Foundation for Statistical Computing: Vienna, Austria, 2020;

27. Hillel, D. Introduction to environmental soil physics; Elsevier Academic Press, 2004; p. 494; ISBN $\underline{\text { 0-12-348655-6. }}$ 
28. Monteith, J.L. Solar radiation and productivity in tropical ecosystems. Journal of Applied Ecology 1972, 9, 747766.

29. Vries, W. de Nutrients trigger carbon storage. Nature Climate Change 2014, 4, 425-427.

30. Fisher, J.B.; Perakalapudi, N.V.; Turner, B.L.; Schimel, D.S.; Cusack, D.F. Competing effects of soil fertility and toxicity on tropical greening. Scientific Reports 2020, 10, 1-10, doi:10.1038/s41598-020-63589-1.

31. Allen, C.D.; David D., B.; McDowell, N.G. On underestimation of global vulnerability to tree mortality and forest die-off from hotter drought in the Anthropocene. Ecosphere 2015, 6, 1-55.

32. Huete, A.R.; Didan, K.; Shimabukuro, Y.E.; Ratana, P.; Saleska, S.R.; Hutyra, L.R.; Yang, W.; Nemani, R.R.; Myneni, R.B. Amazon rainforests green-up with sunlight in dry season. Gephysical Research Letters 2006, 33, 2-5, doi:10.1029/2005GL025583.

33. Saleska, S.R.; Didan, K.; Huete, A.R.; Rocha, H.R. Amazon Forests Green-Up During 2005 Drought. Science 2007, 318, 612, doi:10.1126/science.1146663.

34. Wu, J.; Albert, L.P.; Lopes, A.P.; Restrepo-Coupe, N.; Hayek, M.; Wiedemann, K.T.; Guan, K.; Stark, S.C.; Christoffersen, B.; Prohaska, N. et al. Leaf development and demography explain photosynthetic seasonality in amazon evergreen forests. Science 2016, 351, 972-976, doi:10.1126/science.aad5068.

35. Brum, M.; Vadeboncoeur, M.A.; Ivanov, V.; Asbjornsen, H.; Saleska, S.; Alves, L.F.; Penha, D.; Dias, J.D.; Arag, L.E.O.C.; Barros, F. et al. Hydrological niche segregation defines forest structure and drought tolerance strategies in a seasonal Amazon forest. Journal of Ecology 2018, doi:10.1111/1365-2745.13022.

36. Ouédraogo, D.Y.; Fayolle, A.; Gourlet-Fleury, S.; Mortier, F.; Freycon, V.; Fauvet, N.; Rabaud, S.; Cornu, G.; Bénédet, F.; Gillet, J.F. et al. The determinants of tropical forest deciduousness: disentangling the effects of rainfall and geology in central Africa. Journal of Ecology 2016, 104, 924-935, doi:10.1111/1365-2745.12589.

37. Albert, L.P.; Wu, J.; Prohaska, N.; Camargo, P.B. de; Huxman, T.E.; Tribuzy, E.S.; Ivanov, V.Y.; Oliveira, R.S.; Garcia, S.; Smith, M.N. et al. Age-dependent leaf physiology and consequences for crown-scale carbon uptake during the dry season in an Amazon evergreen forest. New Phytologist 2018, 219, 870-884, doi:10.1111/nph.15056.

38. Koch, G.W.; Stillet, S.C.; Jennings, G.M.; Davis, S.D. The limits to tree height. Nature 2004, 428, 851-854, doi:10.1038/nature02417.

39. Ryan, M.G.; Yoder, B.J. Hydraulic limits to tree height and tree growth: What keeps trees from growing beyond a certain height? BioScience 1997, 47, 235-242, doi:10.2307/1313077.

40. Trugman, A.T.; Detto, M.; Bartlett, M.K.; Medvigy, D.; Anderegg, W.R.L.; Schwalm, C.; Schaffer, B.; Pacala, S.W. Tree carbon allocation explains forest drought-kill and recovery patterns. Ecology Letters 2018, 21, 1552-1560, doi:10.1111/ele.13136.

41. Zhang, B.; Hautier, Y.; Tan, X.; You, C.; Cadotte, M.W.; Chu, C.; Jiang, L.; Sui, X.; Ren, T.; Han, X. et al. Species responses to changing precipitation depends on trait plasticity rather than trait means and intraspecific variation. Functional Ecology 2020, doi:10.1111/1365-2435.13675.

42. Skelton, R.P.; West, A.G.; Dawson, T.E. Predicting plant vulnerability to drought in biodiverse regions using functional traits. Proceedings of the National Academy of Sciences of the United States of America 2015, 112, 57445749, doi:10.1073/pnas.1503376112.

43. Rawls, W.J.; Pachepsky, Y.A.; Ritchie, J.C.; Sobecki, T.M.; Bloodworth, H. Effect of soil organic carbon on soil water retention. Geoderma 2003, 116, 61-76, doi:10.1016/S0016-7061(03)00094-6.

44. Iversen, B.V.; Moldrup, P.; Schjønning, P.; Loll, P. Air and water permeability in differently textured soils at two measurement scales. Soil Science 2001, 166, 643-659, doi:10.1097/00010694-200110000-00001.

45. Priyadarshini, K.V.R.; Prins, H.H.T.; Bie, S.D.; Heitkönig, I.M.A.; Woodborne, S.; Gort, G.; Kirkman, K.; Ludwig, F.; Dawson, T.E.; Kroon, H.D. Seasonality of hydraulic redistribution by trees to grasses and changes in their water-source use that change tree - grass interactions. Ecohydrology 2016, 9, 218-228, doi:10.1002/eco.1624.

(C) 2020 by the authors; licensee MDPI, Basel, Switzerland. This article is an open access article distributed under the terms and conditions of the Creative Commons Attribution (CC-BY) license (http://creativecommons.org/licenses/by/4.0/). 